\title{
EXPERT SYSTEM APLIKASI MONITORING DAN PENGENDALIAN GIZI BERBASIS ANDROID
}

\author{
Giri Gimnastiar ${ }^{1}$, Yossi Indrawati Syuhardi ${ }^{2}$, Intan Vandini ${ }^{3}$ \\ ${ }^{1,2,3}$ Program Studi Teknik Informatika, Fakultas Teknik dan Ilmu Komputer, \\ Universitas Indraprasta PGRI \\ Jalan Raya Tengah No 80, Kelurahan Gedong, Pasar Rebo, Jakarta Timur \\ girigimnastiar2@gmail.com ${ }^{1}$, yossiindrawatisyuhardi@gmail.com², \\ intanvandini@informatikaunindra.org ${ }^{3}$
}

\begin{abstract}
Abstrak
Penelitian ini bertujuan untuk menghasilkan aplikasi sistem pakar berbasis android yang diterapkan pada perangkat mobile serta dapat mendiagnosa penyakit gizi, membantu proses monitoring gizi dan penyembuhannya secara tepat, penelitian ini berfokus juga pada penyelesaian masalah yang berhubungan dengan masalah gizi. Metode pengembangan perangkat lunak untuk expert system monitoring dan pengendalian gizi berbasis android ini dengan menggunakan waterfall model. Dalam pengujian perangkat lunak peneliti menggunakan penilaian dengan pendekatan karakteristik perangkat lunak software product quality model BS ISO 25010. Dalam membuat model rancangan sistem algoritma penyelesaian masalah peneliti menggunakan flowchart dan pseudocode. Perangkat lunak pembangun sistem menggunakan android studio versi 3.6.1 dengan database SQLite. Dalam teknik pengumpulan data peneliti menggunakan cara observasi, studi literatur, dan wawancara. Teknik analisis data dengan menggunakan analisis data kualitatif.
\end{abstract}

Kata Kunci : Artificial intellegence, sistem pakar berbasis android, monitoring dan pengendalian gizi

\begin{abstract}
This study aims to produce an android-based expert system application that is applied to mobile device and can diagnose nutritional disease, assist the process of monitoring nutrition and healing properly, this research also focuses on solving problems related to nutrition problems. The software development method for expert system monitoring and nutritional control based on android uses the waterfall model. In testing the software, researchers used an assessment with the software product quality software characteristic approach of the BS ISO 25010 model. In making problem solving algorithm system design model, researchers use flowcharts and pseudocode. The system builder software uses android studio version 3.6.1 with SQLite database. In the data collection technique, researchers used observation, literature study, and interviews. Data analysis techniques using qualitative data analysis.
\end{abstract}

Keyword : Artificial intelligence, android based expert system, nutritional monitoring and control.

\section{PENDAHULUAN}

Pada era sekarang ini sudah menjadi salah satu gaya hidup masyarakat modern untuk bisa mencoba olahan makanan dan minuman yang sedang menjadi trending di masyarakat luas, kandungan gizi pada makanan dan minuman sangatlah penting peranannya dalam pemenuhan kebutuhan gizi untuk tubuh namun ketika pemenuhan gizi dalam tubuh tidak seimbang maka akan timbul masalah penyakit gizi buruk. Monitoring dan pengendalian gizi harus segera dilakukan untuk meminimalisir akibat dampak dari penyakit gizi buruk, namun dalam kenyataanya pengetahuan masayarakat awam yang minim informasi masih menjadi kendala dalam menghadapi permasalahan terkait penyakit gizi buruk sehingga diperlukan seorang ahli pakar untuk membantu dalam melakukan monitoring yang tepat dalam penyembuhan penyakit gizi buruk [1]. Proses diagnosa penyakit gizi buruk bisa diketahui dari gejala-gejala yang nampak atau dirasakan namun untuk mendapatkan hasil diagnosa dan penanganan yang tepat diperlukan seorang pakar yang memiliki pengetahuan dalam bidang yang berkaitan dengan permasalahan gizi, untuk mengatasi permasalahan gizi ini diperlukan suatu sistem yang mampu mendeteksi dan memberikan penanganan gizi yang tepat layaknya seorang pakar gizi. Android adalah sistem operasi yang sudah sangat familiar untuk 
masayarakat umum terlebih lagi sebuah aplikasi jika dikembangkan pada sistem operasi android akan lebih banyak digunakan dan memberikan manfaat untuk masyarakat mengingat bahwa aplikasi android bisa digunakan oleh siapapun, kapanpun, dan dimanapun. Sistem pakar sudah digunakan dalam dunia kesehatan sejak dahulu kala untuk mendiagnosa suatu penyakit. Permasalahan penyakit gizi bisa diselesaikan dengan sebuah sistem pakar yang bisa dengan mudah digunakan dimanapun, kapanpun, dan oleh siapapun. Dengan pemaparan diatas dibutuhkan cara bagaimana merancang aplikasi sistem pakar menggunakan sistem operasi android pada mobile agar mudah dipahami dan digunakan serta mampu membantu dalam melakukan monitoring dan pengendalian gizi layaknya seorang pakar gizi [2]. Perancangan expert system monitoring dan pengendalian gizi berbasis android dilakukan untuk menciptakan sebuah sistem pakar yang dapat mendiagnosa penyakit gizi dan bisa membantu proses monitoring penyembuhan secara tepat. Manfaat dari sistem pakar monitoring dan pengendalian gizi berbasis android ini untuk memudahkan dalam proses mendiagnosa suatu penyakit gizi dan memberikan tahapan untuk solusi penyembuhan secara efisien.

\section{PENELITIAN RELEVAN}

Beberapa penelitian yang relevan dalam penelitian ini adalah sebagai berikut :

Penelitian oleh Lista Madeso, Don R. Kabo, Johan R.Batmetan dengan judul Rancang Bangun Sistem Pakar Penentuan Status Gizi Pada Balita, program sistem pakar ini dibuat untuk membantu petugas gizi dalam menangani masalah status gizi pada balita, pada penelitian ini menggunakan metode forward chaining dan dikembangkan dengan menggunakan Visual Basic 6.0, hasil akhir dari penelitian ini aplikasi sistem pakar mampu membantu petugas gizi di puskesmas Jailolo dalam mendiagnosa status gizi balita [3]. Penelitian selajutnya penelitian oleh Ahmad Syarifudin, Nurul hidayat, Lutfi Fanani, Jurnal Pengembangan Teknologi Informasi dan Ilmu Komputer Vol.2 No.7 Juli 2018, dengan judul Sistem Pakar Diagnosis Penyakit Pada Tanaman Jagung Menggunakan Metode Nä̈ve Bayes Berbasis Android, program sistem pakar ini dibuat untuk membantu menjadi seorang pakar dalam mendeteksi penyakit jagung, sistem pakar ini diimplementasikan dengan menggunakan sistem operasi android, metode yang digunakan adalah Nä̈ve Bayes Classifier untuk mengukur probabilitasnya, sumber data yang diperoleh dengan menggunakan wawancara dengan seorang pakar, hasil penelitian yang dilakukan menunjukan tingkat akurasi keberhasilan sebesar $96 \%$ [4].

\section{METODE PENELITIAN}

Untuk desian penelitian yang digunakan oleh penulis yaitu dengan menggunakan dua pendekatan karakteristik dimensi Software Product Quality dari model BS ISO 25010. Dua penilaian yang digunakan yaitu penilaian dari sisi Functional Suitability dan Portability untuk menilai efisiensi dari aplikasi menggunakan Maintability di ukur dengan the SIG model. Tempat penelitian dilakukan di salah satu Instalasi Gizi Rumah Sakit Pusat Otak Nasional, Cawang, Jakarta Timur. Dalam teknik pengumpulan data penulis melakukan studi literatur guna mendapatkan gambaran tentang bagaimana cara mengembangkan aplikasi sistem pakar gizi, dilanjutkan dengan melakukan observasi untuk mendapatkan penilaian aplikasi yang ditinjau Functional Suitability, Portability, dan Maintability, proses terakhir penulis melakukan wawancara dengan seorang ahli gizi. Metode perancangan sistem penulis menggunakan model pengembangan perangkat lunak Waterfall Method yang dapat dilihat pada gambar berikut beserta penjelasannya :

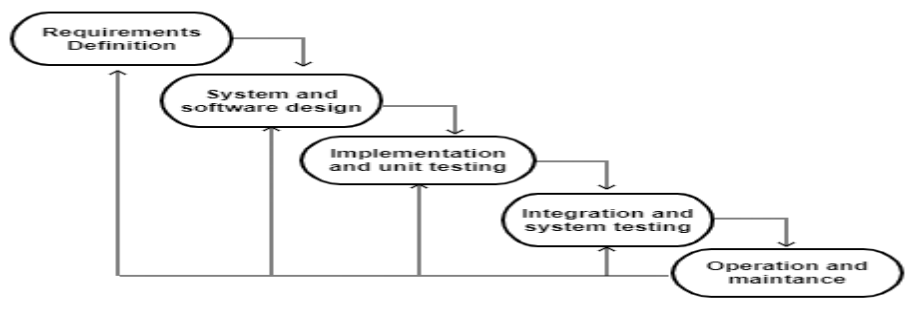

Gambar 1. Waterfall Method Sasmito, (2017) 
Penjelasan :

\section{Requirements Definition}

Pada tahap ini penulis melakukan analisis dan mengumpulkan seluruh kebutuhan software dan hardware dalam mengembangkan aplikasi agar dapat berjalan pada perangkat mobile android, studi literatur juga dilakukan untuk mendapatkan data-data yang dibutuhkan untuk aplikasi.

2. System and Software Design

Berikutnya adalah tahap membuat design aplikasi, antara lain membuat design user interface, design kaidah pengetahuan dari data-data yang sudah didapatkan untuk kebutuhan sistem pakar, selanjutnya membuat design database, yang terakhir membuat design flowchart.

3. Implementation and Unit Testing

Pada tahapan ini peneliti mengimplementasikan seluruh design yang telah dibuat dan menerjemahkannya kedalam salah satu bahasa pemrograman yang mendukung untuk pengembangan aplikasi berbasis android, selanjutnya aturan atau kaidah disimpan kedalam database SQLite.

4. Intergration and System Testing

Tahapan ini adalah tahapan pengujian aplikasi dengan menggunakan faktor kualitas ISO 25010 sebagai standar acuan untuk aplikasi yang telah selesai dibuat,

5. Operation and Maintance

Tahapan terahir dari waterfall method tahapan dimana aplikasi yang sudah selesai dibuat dan diuji dari berbagai indikator selanjutnya aplikasi tersebut digunakan oleh ahli pakar gizi untuk menguji efisiensi dan efektivitas apakah sudah bisa digunakan oleh masayarakat secara mandiri untuk membantu melakukan monitoring dan pengendalian gizi.

\section{HASIL DAN PEMBAHASAN}

Sistem Pakar adalah suatu program komputer yang dirancang untuk dapat melakukan suatu pekerjaan layaknya seorang pakar dengan cara menggunakan pengetahuan, fakta, dan teknik penalaran seorang pakar yang diterapkan pada program komputer untuk menyelesaikan permasalahan pada bidang tertentu "Istilah sistem pakar berasal dari knowledge-based expert system. Istilah ini muncul karena untuk memecahkan masalah, sistem pakar menggunakan pengetahuan seorang pakar yang dimasukan kedalam komputer". Gizi adalah suatu cara mengatur konsumsi makanan untuk tubuh secara normal melalui serangkaian proses yang terstruktur untuk mengatur organ tubuh agar bekerja dengan normal dan baik, menurut Festi [5] mengemukakan bahwa "Gizi (Nutrition) adalah serangkaian proses organisme menggunakan makanan yang dikonsumsi secara normal melalui proses disgesti, absorpsi, transportasi penyimpanan, metabolisme zat-zat yang tidak digunakan untuk mempertahankan kehidupan, pertumbuhan, dan fungsi normal dari organ-organ serta menghasilkan energi". Persoalan masalah gizi bisa timbul karena apa yang diharapkan tentang gizi tidak sesuai dengan kenyataan "Masalah adalah kesenjangan antara harapan yang diinginkan tidak sesuai dengan kenyataan. Demikian juga dengan masalah gizi diartikan sebagai kesenjangan yang terjadi akibat keadaan gizi yang diharapkan tidak sesuai dengan keadaan gizi yang ada [6]. Monitoring atau pemantauan gizi merupakan suatu parameter atau alat ukur untuk mendeteksi dan menentukan status gizi seseorang, [6] dia mengatakan, "Kita mengenal alat ukur yang digunakan untuk keperluan ini antra lain dengan pengukuran status gizi melalui kegiatan Posyandu dengan Kartu Menuju Sehat (KMS). Sebagai alat ukur dan deteksi dini untuk memantau tingkat perkembangan keadaan pada gizi balita, secara umum kita kegiatan pemantauan status gizi. Dari pemantauan dan engukuran ini, kemudian didapatkan status gizi balita masuk kategori gizi lebih, gizi kurang, stunting, atau bahkan gizi buruk". Teorema bayes adalah metode yang paling tepat untuk menghasilkan sebuah keputusan yang tepat, dengan menggunakan pendekatan bayes terhadap probabilitas dapat membantu pakar dalam menentukan sebuah keputusan yang tepat, [7] mengemukakan bahwa "Metode teorema bayes merupakan teknik yang digunakan untuk melakukan analisis dalam pengambilan keputusan terbaik dari sejumlah alternatif". Bentuk teorema bayes dengan evidence tunggal E Hipotesis Tunggal $\mathrm{H}$ adalah :

$$
\mathrm{P}(\mathrm{H} \mid \mathrm{E})=\frac{p(\mathrm{E} \mid \mathrm{H}) \cdot p(\mathrm{H})}{p(\mathrm{E})}
$$


Keterangan :

$\mathrm{p}(\mathrm{H} \mid \mathrm{E})=$ Probabilitas hipotesis $\mathrm{H}$ terjadi jika evidence $\mathrm{E}$ terjadi

$\mathrm{p}(\mathrm{E} \mid \mathrm{H})=$ Probabilitas munculnya evidevce $\mathrm{E}$, jika hipotesis $\mathrm{H}$ terjadi

$\mathrm{p}(\mathrm{H}) \quad=$ Probabilitas hipotesis $\mathrm{H}$ tanpa memandang evidence apapun

$\mathrm{p}(\mathrm{E}) \quad=$ Probabilitas evidence $\mathrm{E}$ tanpa memandang apapun

Bentuk teorema bayes untuk evidence tunggal E dan Hipotesis ganda H1,H2,... Hn Adalah:

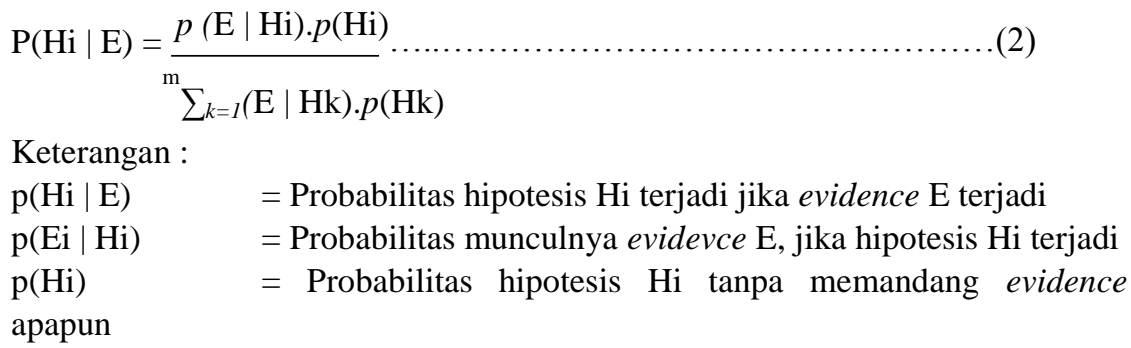

Bentuk Teorema bayes untuk evidence ganda E1,E2,..,Em dan Hipotesis ganda $\mathrm{H} 1, \mathrm{H} 2, \ldots \mathrm{Hn}$ adalah:

$$
p(\mathrm{E} 1 \mathrm{E} 2 \ldots . . . \mathrm{En} \mid \mathrm{Hi}) \cdot \mathrm{p}(\mathrm{Hi})
$$

$$
\mathrm{P}(\mathrm{Hi} \mid \mathrm{E})={ }_{\mathrm{m}} \frac{}{\sum_{k=1} p(\mathrm{E} 1 \mathrm{E} 2 \ldots \ldots . \mathrm{En} \mid \mathrm{Hk}) \cdot \mathrm{p}(\mathrm{Hk})}
$$

Flowchart adalah sekumpulan symbol-symbol standar yang sudah ditentukan dan tidak dapat dirubah oleh pembuat flowchart, flowchart berguna untuk menggambarkan suatu agoritma dari proses awal sampai akhir, "flowchart adalah symbol-symbol atau gambar yang menggambarkan urutan urutan sebuah proses awal sampai dengan akhir. Simbol-simbol flowchart merupakan symbol standart atau sudah memiliki aturan yang tidak dapat diubah oleh pembuat flowchart itu sendiri'"[8]. Dalam membangun expert system Monitoring dan pengendalian gizi berbasis android terdapat beberapa faktor yang perlu diperhatikan, dari faktor tersebut diantaranya adalah bagaimana cara mengembangkan suatu sistem pakar gizi agar bisa diterapkan pada aplikasi mobile berbasis android sehingga mudah untuk dimengerti dan digunakan oleh masyarakat secara mandiri dimanapun, dan kapanpun. Dari proses pengumpulan data yang sebelumnya dilakukan oleh penulis maka didapatkan tabel-tabel gejala serta tabel penyakit yang selanjutnya dari tabel tersebut dapat digunakan untuk merepresentasikan pengetahuan dari seorang pakar ke dalam sistem aplikasi pakar gizi. Tabel tersebut adalah sebagai berikut :

Tabel 1. Jenis Penyakit Gizi

\begin{tabular}{|c|c|}
\hline Kode & Jenis Penyakit \\
\hline P001 & Marasmus \\
\hline P002 & Kwashiorkor \\
\hline P003 & Marasmus-kwashiorkor \\
\hline
\end{tabular}

Tabel 2. Gejala Penyakit Gizi

\begin{tabular}{|l|l|}
\hline Kode & Gejala \\
\hline G001 & Tubuh sangat kurus \\
\hline G002 & Wajah menua \\
\hline G003 & Cengeng \\
\hline G004 & Kulit keriput \\
\hline G005 & Perut cekung \\
\hline G006 & Darah lemah \\
\hline G007 & Detak jantung lemah \\
\hline G008 & Pernafasan lemah \\
\hline G009 & Ada endema \\
\hline
\end{tabular}




\begin{tabular}{|l|l|}
\hline G010 & Wajah membulat \\
\hline G011 & Wajah sembab \\
\hline G012 & Pembesaran hati \\
\hline G013 & Pengecilan otot \\
\hline G014 & Rambut tipis / memerah \\
\hline G015 & Kelainan kulit \\
\hline G016 & Pandangan mata sayu \\
\hline G017 & Pertumbuhan terhambat \\
\hline G018 & Diare \\
\hline
\end{tabular}

Tabel 3. Tabel Aturan Menentukan Jenis Penyakit Gizi

\begin{tabular}{|c|c|c|c|c|}
\hline & & Kod & enis $\mathbf{P}$ & vakit \\
\hline No & Kode Gejala & P001 & P002 & P003 \\
\hline 1. & G001 & $\mathrm{X}$ & $\mathrm{X}$ & $\mathrm{X}$ \\
\hline 2. & G002 & $\mathrm{X}$ & & $\mathrm{X}$ \\
\hline 3. & G003 & $\mathrm{X}$ & & $\mathrm{X}$ \\
\hline 4. & G004 & $\mathrm{X}$ & & $\mathrm{X}$ \\
\hline 5. & G005 & $\mathrm{X}$ & & $\mathrm{X}$ \\
\hline 6. & G006 & $\mathrm{X}$ & & $\mathrm{X}$ \\
\hline 7. & G007 & $\mathrm{X}$ & & $\mathrm{X}$ \\
\hline 8. & G008 & $\mathrm{X}$ & & $\mathrm{X}$ \\
\hline 9. & G009 & & $\mathrm{X}$ & $\mathrm{X}$ \\
\hline 10. & G010 & & $\mathrm{X}$ & $\mathrm{X}$ \\
\hline 11. & G011 & & $\mathrm{X}$ & $\mathrm{X}$ \\
\hline 12. & G012 & & $\mathrm{X}$ & $\mathrm{X}$ \\
\hline 13. & G013 & & $\mathrm{X}$ & $\mathrm{X}$ \\
\hline 14. & G014 & & $\mathrm{X}$ & $\mathrm{X}$ \\
\hline 15. & G015 & & $\mathrm{X}$ & $\mathrm{X}$ \\
\hline 16. & G016 & & $\mathrm{X}$ & $\mathrm{X}$ \\
\hline 17. & G017 & & & $\mathrm{X}$ \\
\hline 18. & G018 & & & $\mathrm{X}$ \\
\hline
\end{tabular}

Tabel 4. Aturan menentukan jenis penyakit gizi dengan probabilitas

\begin{tabular}{|c|c|c|c|}
\hline Nama Penyakit & Gejala & Probabilitas & \\
\hline \multirow{8}{*}{ Marasmus } & Tubuh sangat kurus & 0.5 & \multirow{8}{*}{0.4} \\
\hline & Wajah menua & 0.6 & \\
\hline & Cengeng & 0.4 & \\
\hline & Kulit keriput & 0.6 & \\
\hline & Perut cekung & 0.5 & \\
\hline & Tekanan Darah lemah & 0.4 & \\
\hline & Detak jantung lemah & 0.4 & \\
\hline & Pernafasan lemah & 0.5 & \\
\hline \multirow{9}{*}{ Kwashiorkor } & Tubuh sangat kurus & 0.3 & \multirow{9}{*}{0.3} \\
\hline & Ada endema & 0.6 & \\
\hline & Wajah membulat & 0.5 & \\
\hline & Wajah sembab & 0.5 & \\
\hline & Pembesaran hati & 0.6 & \\
\hline & Pengecilan otot & 0.5 & \\
\hline & Rambut tipis / memerah & 0.4 & \\
\hline & Kelainan kulit & 0.5 & \\
\hline & Pandangan mata sayu & 0.4 & \\
\hline \multirow{11}{*}{$\begin{array}{c}\text { Marasmus- } \\
\text { Kwashiorkor }\end{array}$} & Tubuh sangat kurus & 0.4 & \multirow{11}{*}{0.4} \\
\hline & Wajah menua & 0.3 & \\
\hline & Cengeng & 0.3 & \\
\hline & Kulit keriput & 0.3 & \\
\hline & Perut cekung & 0.4 & \\
\hline & Tekanan Darah lemah & 0.3 & \\
\hline & Detak jantung lemah & 0.3 & \\
\hline & Pernafasan lemah & 0.3 & \\
\hline & Ada endema & 0.3 & \\
\hline & Wajah membulat & 0.4 & \\
\hline & Wajah sembab & 0.4 & \\
\hline
\end{tabular}




\begin{tabular}{|c|c|c|}
\hline \multirow{4}{*}{} & Pembesaran hati & 0.4 \\
\cline { 2 - 3 } & Pengecilan otot & 0.3 \\
\cline { 2 - 3 } & Rambut tipis / memerah & 0.4 \\
\cline { 2 - 3 } & Kelainan kulit & 0.3 \\
\cline { 2 - 3 } & Pandangan mata sayu & 0.4 \\
\cline { 2 - 3 } & Pertumbuhan terhambat & 0.5 \\
\hline
\end{tabular}

Analisis proses perhitungan manual sebagai contoh jika gejala yang dipilih kulit keriput, tekanan darah lemah, dan pernafasan lemah maka kode gejala yang terpilih yaitu G004, G006 dan G008 perhitungan manualnya adalah sebagai berikut :

Menghitung total Bayes pada probabilitas penyakit Marasmus

1. $\mathrm{P}\left(\mathrm{H}_{1} \mid \mathrm{E}_{1} \mathrm{E}_{2} \mathrm{E}_{3}\right)$

$0.4 * 0.6 * 0.4 * 0.5$

$=$

$0.4 * 0.6 * 0.4 * 0.5+0.3 * 0.0 * 0.0 * 0.0+0.4 * 0.3 * 0.3 * 0.3$

$=$ Total nilai probabilitas pada penyakit Marasmus adalah sebesar $=81.36 \%$

Menghitung total Bayes pada probabilitas penyakit Kwashiorkor

2. $\mathrm{P}\left(\mathrm{H}_{2} \mid \mathrm{E}_{1} \mathrm{E}_{2} \mathrm{E}_{3}\right)$

$0.3 * 0.0 * 0.0 * 0.0$

$0.3 * 0.0 * 0.0 * 0.0+0.4 * 0.6 * 0.4 * 0.5+0.4 * 0.3 * 0.3 * 0.3$

$=$ Total nilai probabilitas pada penyakit Kwashiorkor adalah sebesar $=0.0 \%$

Menghitung total Bayes probabilitas pada penyakit Marasmus-Kwashiorkor

3. $\mathrm{P}\left(\mathrm{H}_{3} \mid \mathrm{E}_{1} \mathrm{E}_{2} \mathrm{E}_{3}\right)$

$0.4 * 0.3 * 0.3 * 0.3$

$=\overline{0.4 * 0.3 * 0.3 * 0.3+0.3 * 0.0 * 0.0 * 0.0+0.4 * 0.6 * 0.4 * 0.5}$

$=$ Total nilai probabilitas pada penyakit Marasmus adalah sebesar $=18.37 \%$

Dari hasil perhitungan diatas dapat ditarik suatu kesimpulan bahwa penyakit Marasmus menempati penyakit paling mungkin terjadi jika dilihat dari gejala yang nampak atau dirasakan karena penyakit Marasmus memiliki nilai probabilitas tertinggi yaitu sebesar $81.36 \%$ sedangkan penyakit Marasmus-Kwashiorkor menempati posisi kedua dengan nilai probabilitas sebesar $18.37 \%$, untuk penyakit Kwashiorkor penyakit yang memiliki nilai probabilitas $0.0 \%$ yang berarti bahwa tidak mungkin terkena penyakit Kwashiorkor dari gejala yang dipilih tersebut. 


\section{Algoritma Penyelesaian Masalah dengan Flowchart}

Berikut adalah algoritma penyelesaian masalah diagnosa penyakit gizi dengan flowchart Setelah flowchart dan design aplikasi selesai dibuat maka dilakukan pengkodean pada aplikasi sistem pakar monitoring dan pengendalian gizi berbasis android, pada pengkodean penulis menggunakan bahasa pemrograman java dalam mengembangkan aplikasi monitoring dan pengendalian gizi berbasis android, berikut tampilan user interface dari aplikasi monitoring dan pengendalian gizi berbasis android

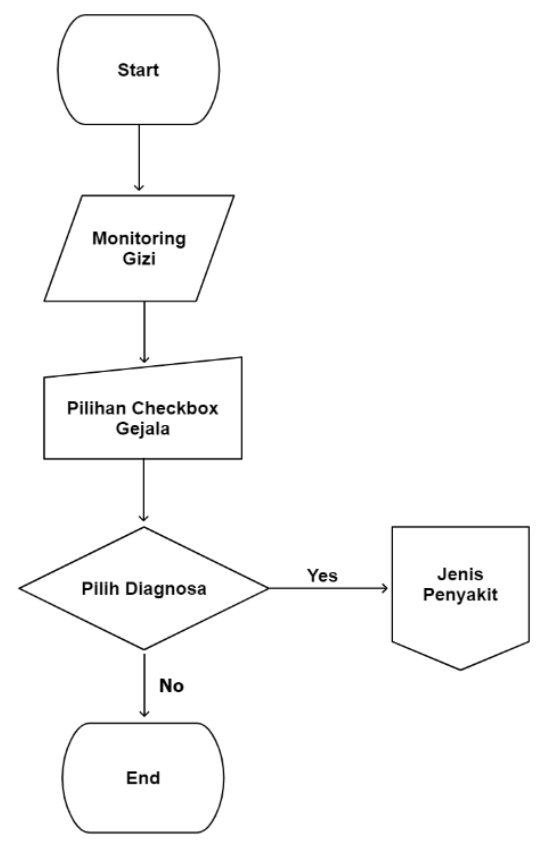

Gambar 2. Flowchart Cek Gejala Klinis

\section{Tampilan Layar}

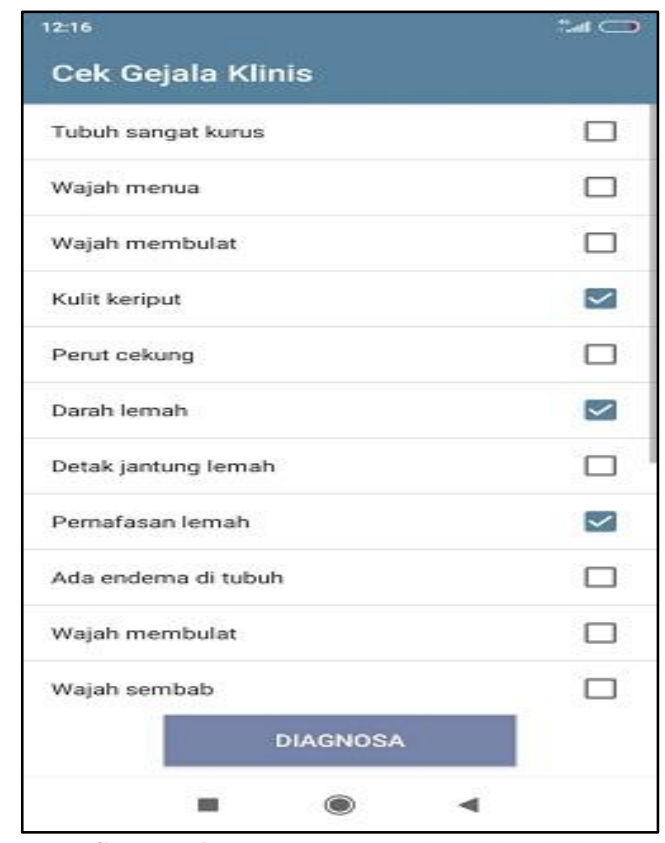

Gambar 3. User Interface Cek Gejala Klinis 


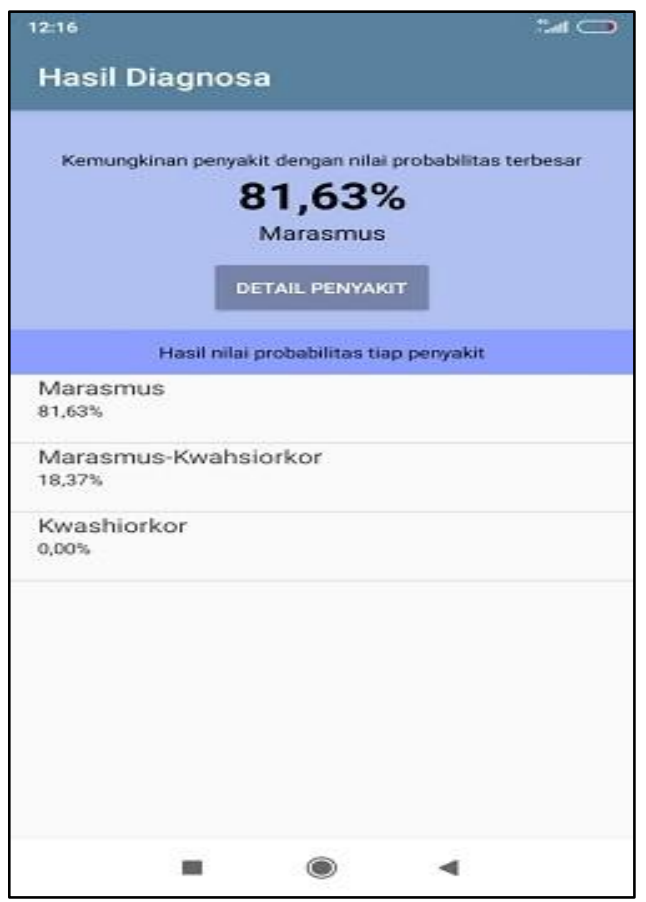

Gambar 4. User Interface Hasil Diagnosa

\section{SIMPULAN}

Aplikasi sistem pakar monitoring dan pengendalian gizi berbasis android ini berhasil mendiagnosa penyakit gizi dengan hasil diagnosa penyakit yang cukup baik sehingga dari penelitian tersebut dapat ditarik suatu kesimpulan bahwa aplikasi sistem pakar monitoring dan pengendalian gizi sudah layak digunakan dan dapat membantu seseorang dalam melakukan konsultasi gizi.

\section{DAFTAR PUSTAKA}

[1] S. Pari'i, H.M. dan Wiyono, Penilaian Status Gizi. Jakarta: Pusat Pendidikan Sumber Daya Manusia Kesehatan, 2017.

[2] R. Dewi, "Sistem Pakar Diet Sehat Bertipe Genotipe Menggunakan Metode Certainty Factor," Sisfotenika, vol. 4, no. 2, pp. 163-174, 2014.

[3] R. Suganda, E. Sutrisno, and I. W. Wardana, "Rancang Bangun Sistem Pakar Penentuan Status Gizi pada Balita Menggunakan Metode Forward Chaining," J. Chem. Inf. Model., vol. 53, no. 9, pp. 1689-1699, 2013.

[4] A. Syarifudin et al., "Sistem Pakar Diagnosis Penyakit Pada Tanaman Jagung Menggunakan Metode Naive Bayes Berbasis Android," Semesta Tek., vol. 21, no. 2, pp. 1492-1500, 2018.

[5] P. W. Festi, Buku Ajar Gizi dan Diet. Surabaya: UMSurabaya Publishing, 2018.

[6] M. Setyowati and R. Astuti, "Mapping the Nutritional Status of Children in Support of," J. Kesehat. Masy., vol. 10, no. 2, pp. 110-121, 2015.

[7] I. M. A. Wirawan, Metode Penalaran Dalam Kecerdasan Buatan. Depok: PT Raja Grafindo Persada, 2017.

[8] R. Y. Endra, Belajar Mudah Algoritma Pemrograman Java. Surabaya: CV. Garuda Mas Sejahtera, 2016. 